\title{
An end-user perspective on smart home energy systems in the PowerMatching City demonstration project
}

\author{
Daphne Geelen ${ }^{1}$, Manon Vos-Vlamings ${ }^{2,3}$, Faidra Filippidou ${ }^{1}$, \\ Albert van den Noort $^{4}$, Maike van Grootel ${ }^{5}$, \\ Henri Moll ${ }^{3}$, Angèle Reinders ${ }^{1,6}$, David Keyson ${ }^{1}$ \\ ${ }^{1}$ Delft University of Technology \\ Delft, The Netherlands \\ ${ }^{2}$ Hanzehogeschool Groningen \\ Groningen, The Netherlands \\ ${ }^{3}$ University of Groningen \\ Groningen the Netherlands \\ ${ }^{4}$ DNV KEMA \\ Groningen, The Netherlands \\ ${ }^{5}$ Essent \\ Den Bosch, The Netherlands \\ ${ }^{6}$ University of Twente \\ Enschede, The Netherlands
}

\begin{abstract}
In discussions on smart grids, it is often stated that residential end-users will play a more active role in the management of the electric power system. Experience in practice on how to empower end-users for such a role is however limited. This paper presents a field study in the first phase of the PowerMatching City project in which twenty-two households were equipped with demand-response-enabled heating systems and white goods. Although end-users were satisfied with the degree of living comfort afforded by the smart energy system, the user interface did not provide sufficient control and energy feedback to support an active contribution to the balancing of supply and demand. The full potential of demand response was thus not realized. The second phase of the project builds on these findings by design, implementation and evaluation of an improved user interface in combination with two demand response propositions.
\end{abstract}

Index Terms - demand response, smart grid, user interface, enduser behavior, energy balance

\section{INTRODUCTION}

In the ongoing transition from a centralized electricity grid towards a more decentralized and intelligent electricity system, residential end-users are expected to play a more active role in the management of the electric power system. Evaluative reports on smart grid developments, such as [1] and [2], highlight the importance of products and services that are acceptable for end-users. However, there is a lack of knowledge on how smart grid products and services could support end-users in taking up a more active role [3]. Studies evaluating acceptance and perception of smart grid technology based on scenarios, have indicated conditions for end-users to buy smart appliances [4] and provided insight in perceived advantages and disadvantages of a smart home [5]. This paper presents a field study with 22 households that were actually using smart grid products and services as part of the PowerMatching City pilot project.

This project is co-financed by the IPIN subsidy program of the Ministry of Economic Affairs in The Netherlands.

Project partners are: Enexis, Essent, Gasunie, ICT Automatisering, DNV KEMA, TNO, Hanzehogeschool Groningen, Technische Universiteit Delft and Technische Universiteit Eindhoven.
In recent years other pilot projects have been initiated that implement smart grid technology at the household level, such as the E-DEMA project in Germany [6] and the Linear project in Belgium [7]. These projects are of a larger scale than PowerMatching City, but field study results concerning endusers' perspective on the implemented products and services are lacking. Therefore, the findings from PowerMatching City could contribute to the ongoing knowledge development needed for successful design of products and services for households in smart grids..

In the following section the smart energy system design of PowerMatching City is described. In section 3, the research scope and questions will be explained. Section 4 presents the results. Section 5 addresses how the results are used in the second phase of the project. Section 6 presents the conclusion.

\section{POWER MATCHING CITY}

The overall goal of the Power Matching City project was to demonstrate a full concept solution of a smart energy system. The first phase started in 2007. The technical functionality of the smart energy system was built and tested. Furthermore, research took place to gain insight in the involvement of the end-users with the smart energy system. The lessons from the first phase were used for the second phase of the project, in which additional households became part of PowerMatching City by June 2012. The description below is based on the situation in the first phase of the project on which the field study presented in this paper is based.

PowerMatching City consists of a cluster of 22 households that are connected in a smart energy system. The components of this system at household level are described below. Table 1 provides an overview of the configurations. In this paper, the combination of the components will be referred to as the 'home energy system' to differentiate from the 'smart energy system' which refers to the overall system the households are 
connected in. The underlying premises for the operation of the home energy system were that (1) operation would be automated as much as possible and (2) that the participating households would not experience a loss in every-day living comfort in relation to the use of their electric appliances and the available heat for hot water and space heating. In addition to the 22 home energy systems, several other devices are connected to the cluster, such as electric vehicles, a wind turbine and a number of simulated households [9].

\section{A. Demand response heating systems and appliances}

Two types of heating systems were implemented. Twelve households were equipped with a hybrid heat pump system (HP), which combines an air-source heat pump with a condensing boiler. Ten households were equipped with gas fired micro-cogeneration units (mCHP). Both systems include a hot water tank of 210 liters to store heat that is not used directly. This enables the decoupling in time of electricity and heat consumption from electricity and heat production.

Twelve households were equipped with a smart dishwasher and washing machine. These could be controlled remotely by the smart energy system's coordination mechanism. The coordination is based on the situation in the smart grid in combination with end-user settings, such as the time by which an appliance should be finished washing. In the first phase the use of the appliances as 'smart' appliances was limited to the dishwasher, due to communication problems between the devices.

\section{B. Renewable energy sources}

The renewable energy production in the PowerMatching City cluster consists of photovoltaic (PV) solar energy for each household and wind energy. Four households produce electricity with their own PV solar installation. The other households have 'virtual PV production' via sub-metering of a PV system on a building in Groningen. In this way the effect of the PV production can be taken into account at the household level. In addition to PV solar energy, a wind turbine was connected to the cluster. The production of this wind turbine $(2,5 \mathrm{MW})$ was scaled down virtually to match the consumption levels of the households.

Table 1: Configuration of technologies in households

\begin{tabular}{|c|c|c|c|c|c|c|c|}
\hline \multicolumn{8}{|c|}{$\begin{array}{c}\text { Total nr of households: } \\
22\end{array}$} \\
\hline \multicolumn{4}{|c|}{$\begin{array}{c}\mathbf{H P} \\
12 \\
\end{array}$} & \multicolumn{4}{|c|}{$\underset{10}{\mathbf{m C H P}}$} \\
\hline \multicolumn{2}{|c|}{$\begin{array}{c}\text { Own PV } \\
2 \\
\end{array}$} & \multicolumn{2}{|c|}{$\begin{array}{c}\text { Virtual PV } \\
10 \\
\end{array}$} & \multicolumn{2}{|c|}{$\begin{array}{c}\text { Own PV } \\
2 \\
\end{array}$} & \multicolumn{2}{|c|}{$\begin{array}{c}\text { Virtual PV } \\
8 \\
\end{array}$} \\
\hline \multicolumn{2}{|c|}{ Smart appliances } & \multicolumn{2}{|c|}{ Smart appliances } & \multicolumn{2}{|c|}{ Smart appliances } & \multicolumn{2}{|c|}{ Smart appliances } \\
\hline Yes & No & Yes & No & Yes & No & Yes & No \\
\hline 1 & 1 & 5 & 5 & 1 & 1 & 4 & 4 \\
\hline
\end{tabular}

\section{Automatic coordination mechanism PowerMatcher}

The energy supply and demand in the network of PowerMatching City is balanced automatically with an agentbased algorithm called 'PowerMatcher' developed by TNO. Different types of agents together coordinate the matching of supply and demand of electricity in the network based on market mechanisms. An ICT interface layer between the devices and the PowerMatcher allows a device agent to trade the consumed or produced electricity on a local market. The agent aims to enable economically optimal operation of the device within the conditions set by the end-user, such as to provide a minimum room temperature or to have clean dishes within eight hours.

The coordination mechanism can be adjusted to suit different goals and needs of the actors in the smart grid. To this end, the objectives and trading conditions of the agents are modified. For example, PowerMatcher could instead of optimizing for least costs for the end-users independent of the sources of production, be set to maximize consumption of self-produced electricity. A comprehensive description of PowerMatcher- technology was given by Kok et al [10].

\section{User interface}

The term user interface refers to the interface where interaction between end-users and technical system takes place. In the first phase of PowerMatching City, the interface of the home energy system consisted of the following parts:

1. A manual thermostat by which end-users could set the desired room temperature.

2. The interfaces of the smart appliances enable the end-user choose the operation mode of the appliance, i.e., automated via PowerMatcher or manual.

3. An Energy Portal was available after login via the Internet, with information about electricity production and consumption at household and cluster level (Figure 1).

4. A community portal enabled online interaction between end-users.

\section{RESEARCH APPROACH}

The research presented in this paper is of an exploratory and qualitative nature, because the smart energy system implemented in PowerMatching City is under continuous development. Furthermore the group of participants is not a representative sample of households for the Netherlands. The sample consisted of 22 participating households. The participants have higher education levels and higher income than average. Most participants live in detached houses, which is not the case for the majority of the Dutch population. Overall, the participants also show more concern for environmental problems and are more aware of their energy consumption. Due to the little knowledge available about endusers in smart grids, the project nevertheless provided a valuable opportunity to gain insight in end-user needs and their energy consumption and production in a smart grid context.

The questions addressed in this paper are:

1. What were the experiences of the end-users concerning the use of the home energy system?

2. To what extent did the home energy system affect end-user behavior?

3. What was the energy balance in the cluster of households?

For the first and second question information was available from a number of interviews, co-design workshops, focus groups and questionnaires. These took place from November 2010 , just before the systems were installed in the houses until December 2012. The response rates differ per research 
activity, ranging from five to sixteen households. To answer the third question, energy consumption and production data of 21 households were analyzed and aggregated to cluster level data. Detailed measurements at 5 minutes basis were used, taken from April 1 $1^{\text {st }}, 2012$ to January $31^{\text {st }}, 2013$.

\section{RESULTS}

\section{A. Experiences with the home energy system}

The most drastic change for the participating households was the replacement of their heating system. Two years after implementation of the new heating system, the households indicated that they were satisfied. The households had become familiar with the new system. The comfort levels, in terms of room temperature and hot water temperature, were according to their expectations. In the case of one household equipped with a low-temperature heating system, the desired comfort levels could not be achieved.

While the comfort levels in the households were generally found to be satisfactory, the majority of end-users (10 out of 15 respondents) were not satisfied with the thermostat. Many of them had been using a programmable thermostat before. Having to use a manual thermostat for the PowerMatching City project was considered to be a downgrade.

With regard to the smart dishwasher, the comments made by two end-users in interviews held during November 2012, indicated that the smart dishwasher operation had not changed their normal way of using the appliance. They would turn on the dishwasher at night in smart operation mode and the dishes would be done in the morning, i.e. within the 8-hour timeslot for smart operation. The observed practice of these end-users demonstrates that though they adapted their behavior to use the smart dishwasher they were not consciously "playing a smart energy game".

The achievement of energy-related goals appeared to be important for several of the participating households. About half of the households indicated that their main goal was to save energy or energy costs. Other goals that were mentioned in the course of the project included trading energy and minimizing the consumption of electricity from the grid by using self-produced energy.

Despite the available Energy Portal, see figure 1, the households reported that they lacked insight in energy consumption and production. The Energy Portal was visited frequently when the smart home system had been recently installed. End-users indicated that they visited the portal to gain insight in the operation of the home energy system. After two years, 7 out of 16 interviewed households indicated that they did not or hardly ever view the Energy Portal. The reasons given were that it did not offer them new information or information that supported them in achieving their energy related goal or lead to new ways of interacting with the system. One of the end-users stated in an interview in 2011: "I expected to be able to save energy with help of information on the portal'. The end-users that did visit the website on a regular basis, ranging from twice a week to once a month, were interested in the amounts of energy used and produced, comparison with their own meter readings or check whether the system was working.
The households indicated that they did not notice that they took part in a local smart grid. In questionnaires in September 2012, end-users (11 out of 16) stated they would like to have more sense of being part of a smart grid. Half of the respondents ( 8 out of 16) stated that they would want to be more actively involved in the smart grid by means of (a) insight in how the system works and when and how automatic matching of supply and demand takes place, and (b) ability to act consciously based on the balance of supply and demand, for example by shifting loads or trading energy. The other half of the respondents ( 8 out of 16) indicated to be end-users were satisfied with the current level of activity, stating for example that "The current automated operation is fine" or "It's sufficient to once set the system boundaries".

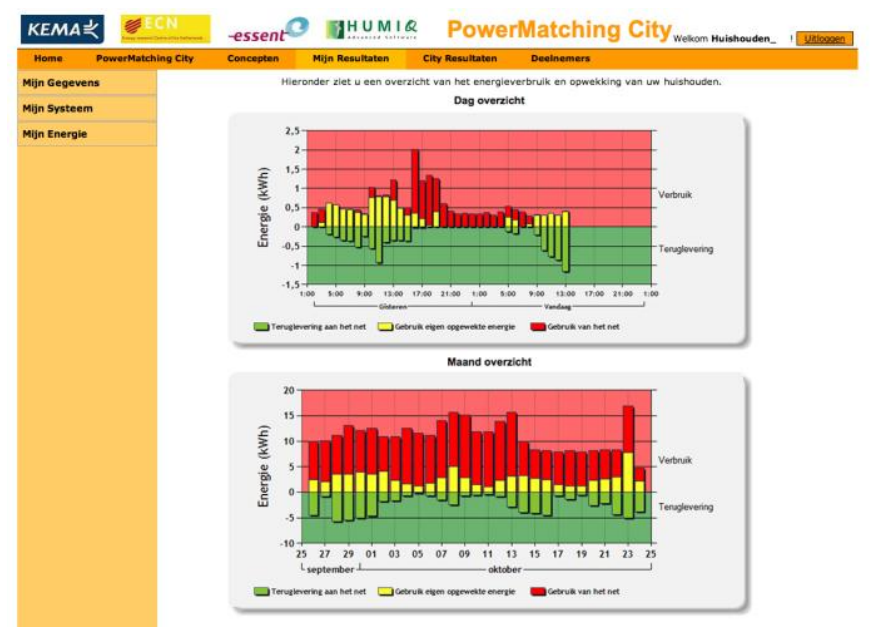

Figure 1. Energy Portal, showing the energy consumption and production of the last day (top) and month (bottom) of a household.

The community portal was intended to complement the information at the household level by providing: (1) information at the cluster level and (2) exchange of information between the participating households. The amount of participants attending a design session for the community website and the launch of the community website, was about 10 households for both events. This indicates that there was an interest among the end-users in a community platform. In practice however little interaction took place once the website was implemented, resulting in 24 posts and 46 comments by end-users over a period of 9 months. The messages that were posted related to (1) technical problems, (2) questions about project events such as the placement of a new digital meter, (3) sharing of energy consumption data and (4) an offer to help others to gain insight in the developments of their energy consumption over the past years.

Evaluation in a focus group (7 respondents) and interviews (5 respondents) after the community portal had been running for six months, indicated that although the idea of a community website for sharing and comparing information was found interesting, the respondents lacked incentives to use the community website to post messages. To gain more insight in the potential of social interaction between households in smart energy systems, further research would be required in a context where households have more information and control of the home energy system. 


\section{B. Effects on energy-related behavior}

The households were asked whether their energy consumption behavior had changed due to the implementation of the smart energy system via a questionnaire September 2012. Nine of the sixteen respondents indicated that they became more conscious of their energy consumption. This suggests that they have continued or intensified their existing energy saving activities. The other respondents indicated that no changes took place. Reasons given for this were: "Difficult to control", "We cannot program the dishwasher and washing machine and still use electricity as if we have day-and night tariffs".

Concerning the use of the thermostat, three households indicated in interviews that they did not make use of the standby function when leaving the house. They wanted the house to be warm by the time they arrived back home, which would be within the 7 hours stand-by time. Such use of the thermostat may have resulted in higher energy consumption than before implementation of the smart home energy system.

\section{Energy balance in the cluster}

The energy consumption and production of the households were analyzed to quantify the energy balance in the cluster of households in PowerMatching City. Energy balance in this paper refers to the comparison between levels of energy production and consumption. The energy production in PowerMatching City in this period consisted of the production from the PV solar panels and the micro-cogeneration units. The energy balance information could furthermore be used to support communication with end-users. Weekly 'energy reports' about the energy consumption and production in the cluster were published on the community website.

Two quantitative indicators were used to characterize the relations between the energy consumption and production in the cluster of households. The first indicator describes the amount of consumption from electricity produced in the cluster compared to the total consumption. The second indicator describes how much of the electricity produced in the cluster is consumed within the cluster.

The average electricity consumption from April 2012 to January 2013 was $12.2 \mathrm{kWh}$ (SD 1,17 kWh) per day per household. This is higher than the average Dutch energy consumption of $3500 \mathrm{kWh}$ per year, 9,6 kWh per day [11]. The average electricity production was $2.4 \mathrm{kWh}$ (SD 0,71 $\mathrm{kWh}$ ) per day per household.

Concerning the first indicator, $2 \%$ to $24 \%$ of the consumed electricity was covered with electricity produced in the cluster. The majority of the energy consumed in PowerMatching City was thus supplied from the central grid. Figure 2 illustrates the indicator scores over the measured period. The overall low scores can be explained by the system design, which was not designed to cover the entire electricity demand with production capacity in the cluster. The highest scores are in July and August, caused by the high production of PV solar energy in these months. The indicator for May 2012 is low compared to the other months because the virtual PV production was not available in that month.
With regard to the consumption of the electricity that was produced in the cluster, the results indicate that the majority of the energy produced in the cluster is actually used within the cluster. The second indicator scores ranged from $39 \%$ to $76 \%$. Similar to the first indicator, the highest percentages correspond to the months July and August, when the production of solar energy was highest. Figure 3 shows the percentages over time.

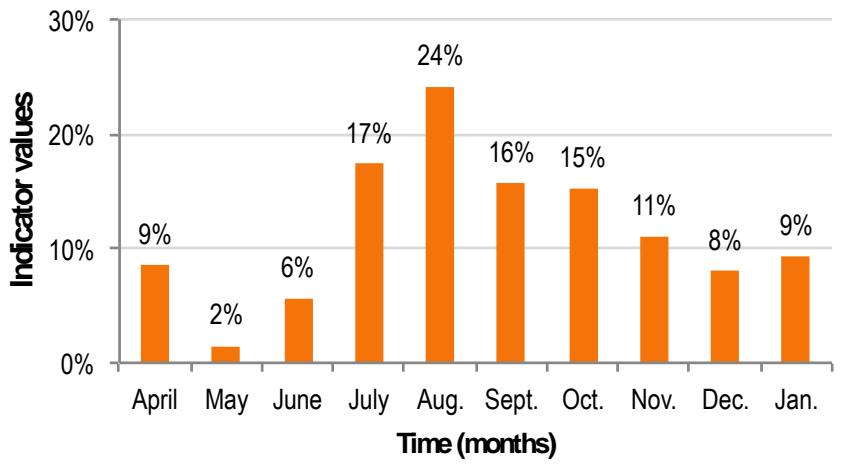

Figure 2. Fraction of consumption of electricity that was produced in the cluster in relation to the total electricity consumption. In May the virtual PV production was not available, hence the lower percentage that month.

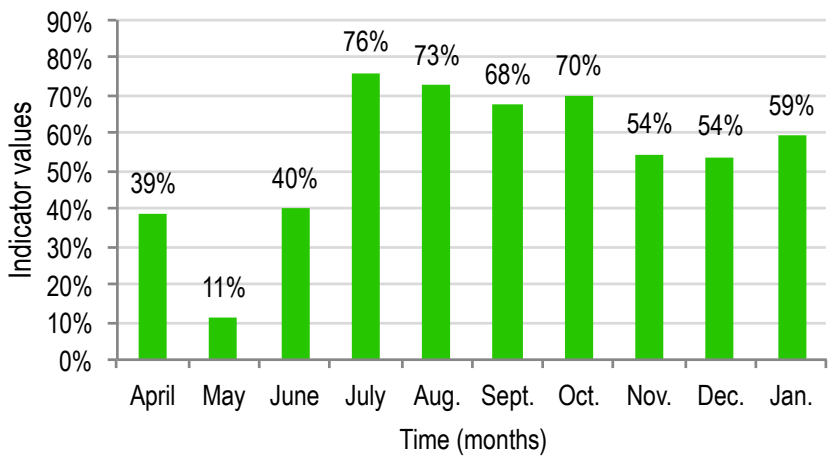

Figure 3. Fraction of consumption of electricity that was produced in the cluster in relation to the total electricity production in the cluster. In month May the virtual PV production was not available, hence the lower percentage that month.

\section{MAIN FINDINGS}

From the end-user perspective, the smart energy system appeared to be running in the background. The findings indicate that the end-users in general were satisfied with the comfort levels provided. However, several end-users appeared to miss the insight and controls that could support them in reaching their household's energy-related goals, such as to save energy and to maximize consumption of locally produced solar energy. Along the same line, the results from the intervention with the community website suggested that there was little incentive to become a more active participant in the smart grid.

The energy balance analysis allowed for insight in the interplay between energy production and consumption in PowerMatching City in different seasons. This insight can be used for the optimization of the smart energy system as well as for communication about the performance of the system to 
the end-users. For example, when a higher amount of consumption from energy produced in the cluster is desired (indicator 2), additional demand response of the households is required to match moments of energy consumption to availability of electricity produced in the cluster. This can be achieved automatically via the PowerMatcher algorithm as well as via information and incentives supporting the endusers to shift their energy consumption in time.

\section{CONTINUATION OF RESEARCH IN PHASE 2}

In the second phase of PowerMatching City, running from 2011 to 2014, an additional 18 households become part of the smart energy system. These households have similar houses and are located in the same street. Based on the lessons from the first phase an in-home display was developed together with the participants in order to improve the user interface, as well as to test two propositions for demand response.

The user interface is considered key to achieve optimal demand response in the smart energy system. Three levels for demand response are discerned, for which sufficient insight and feedback for end-users have to be available. The first level is automated demand response, which functions on the background. This has been applied with the heating systems. End-users are given the means to set boundary conditions, i.e. thermostat settings, and receive feedback about energy consumption and production. The second level consists of semi-automated demand response via smart appliances. Endusers receive the information that should enable them to plan appliance operation, such as electricity tariffs and when locally produced electricity is available. The third level can be described as manual demand response and concerns the use of 'normal' appliances. The provided information and feedback are similar to the information for semi-automated demand response.

In the second phase of PowerMatching City the households are provided with one of two business propositions for demand response. The propositions aim to support the endusers in reaching a goal related to their participation in the smart grid: (1) consumption of locally produced energy or (2) minimizing costs. The first proposition 'Together More Sustainable' aims to make optimal use of the renewable energy that is produced within the cluster, thereby decreasing the dependence of other energy sources for the participating households. At the same the proposition fosters a sense of being part of a smart grid community in which energy production and consumption is balanced locally. The second proposition is called 'Smart Cost Saving' and is aimed at minimizing energy costs by using energy at moments when prices are low. The PowerMatcher is set to automate operations and provide information for an in-home display according the proposition the household is provided with.

The research will focus on the attractiveness of the propositions for the end-users and their influence on energyrelated behavior.

\section{CONCLUSION}

The results of this study suggest that while the end-users were participating in the smart energy system by means of the implemented technology, the end-users themselves could not become more active in the management of the energy system at household or cluster level. A certain level of automation may be required for proper functioning of a smart energy system. However, to reach its full potential more active involvement of end-users may be beneficial. End-users could deliver an active contribution to the balancing of supply and demand when they are enabled with information, control and incentives that suit their needs and goals. This means that research about how end-users make use of the smart energy system is requisite. Also inclusion of the end-users in the design process, as used in this project for development of an improved user interface, would contribute to valuable insights for the development of smart grid products and services for households.

The results presented in this paper are specific to the situation in the project due to the available sample and data. The research in the second phase of the project will provide further insight in business propositions in combination with smart grid technology. Complementary research, quantitative and qualitative, would be required to continue building up knowledge for product and service design in support of endusers taking up a more active role in smart grids.

\section{REFERENCES}

[1] V. Giordano, F. Gangale, G. Fulli, and M. Sánchez Jiménez, "Smart Grid projects in Europe: lessons learned and current developments," Joint Research Centre of the European Comission, Institute for Energy, 2011.

[2] International Energy Agency, "Technology Roadmaps - Smart Grids," OECD/IEA, 2011.

[3] D. Geelen, A. Reinders, and D. Keyson, "Empowering the end-user in smart grids: Recommendations for the design of products and services," Energy Policy, In press, 2013.

[4] W. Mert and W. Tritthart, "Get smart! Consumer acceptance and restrictions of Smart Domestic Appliances in Sustainable Energy Systems," TRANSPOSE Midterm Conference. Muenster, 2009.

[5] A.-G. Paetz, E. Dütschke, and W. Fichtner, "Smart Homes as a Means to Sustainable Energy Consumption: A Study of Consumer Perceptions," Journal of Consumer Policy, vol. 35, p. 23-41, 2012.

[6] H.-J. Belitz, S. Winter, C. Mu $\square$ ller, N. Langhammer, R. Kays, C. Wietfeld, and C. Rehtanz, "Technical and Economic Analysis of Future Smart Grid Applications in the E-DeMa Project," in Proc. $20123 r d$ IEEE PES Innovative Smart Grid Technologies Europe.

[7] B. Dupont, P. Vingerhoets, P. Tant, K. Vanthournout, W. Cardinaels, T. De Rybel, E. Peeters, and R. Belmans, "LINEAR Breakthrough Project: Large-Scale Implementation of Smart Grid Technologies in Distribution Grids," in Proc. 2012 3rd IEEE PES Innovative Smart Grid Technologies Europe.

[8] F. Bliek, A. van den Noort, B. Roossien, R. Kamphuis, J. de Wit, J. van der Velde, and M. Eijgelaar, "PowerMatching City, a living lab smart grid demonstration," in Proc. 2010 IEEE PES Innovative Smart Grid Technologies Conference Europe.

[9] F. Bliek, A. van den Noort, B. Roossien, R. Kamphuis, J. de Wit, J. van der Velde, and M. Eijgelaar, "The role of natural gas in smart grids," Journal of Natural Gas Science and Engineering, vol. 3, no. 5, pp. 608616, 2011.

[10] K. Kok, B. Roossien, P. MacDougall, O. van Pruissen, G. Venekamp, R. Kamphuis, J. Laarakkers, and C. Warmer, "Dynamic pricing by scalable energy management systems - Field experiences and simulation results using PowerMatcher," in Proc. 2012 IEEE Power and Energy Society General Meeting.

[11] "Milieucentraal - Gemiddeld energieverbruik." [Online]. Available: www.milieucentraal.nl. [Accessed: 14-Jun-2013]. 